Revista Brasileira de Agricultura Irrigada v.10, $\mathrm{n}^{\circ} .2$, p. 586 - 597, 2016

ISSN 1982-7679 (On-line)

Fortaleza, CE, INOVAGRI - http://www.inovagri.org.br

DOI: $10.7127 /$ rbai.v10n200408

Protocolo 408.16 - 02/03/2016 Aprovado em 12/04/2015

\title{
ÁREA FOLIAR DA FIGUEIRA EM TRÊS AMBIENTES DE CULTIVO, SOB FERTIRRIGAÇÃO DE BIOFERTILIZANTE BOVINO
}

\author{
Cristiane Aires Celedonio ${ }^{1}$, José Francismar de Medeiros $^{2}$, Thales Vinícius de Araújo Viana ${ }^{3}$, \\ Kleiton Rocha Saraiva ${ }^{4}$, Gregório Hermes Paiva de Lima ${ }^{5}$
}

\section{RESUMO}

Objetivou-se determinar o tipo de ambiente e a dose de biofertilizante bovino aplicado via fertirrigação que proporcionem a maior área foliar da figueira nas condições climáticas do semiárido. Este trabalho foi desenvolvido na Chapada do Apodi, Ceará. O delineamento utilizado foi em blocos completos ao acaso, com quatro repetições. Os tratamentos consistiram da combinação de três tipos de ambientes (latada, estufa e campo) e cinco níveis de adubação: quatro doses de biofertilizante e uma adubação mineral, aplicadas aos 15, 30, 45, 60, 75 e 90 dias após poda de formação. A solução para cada dose foi obtida pela diluição do biofertilizante em água nas seguintes proporções: $\mathrm{D}_{0}=$ zero parte de biofertilizante e 5 partes de água, $\mathrm{D}_{1}=4$ partes de água e 1 de biofertilizante $(20 \%), \mathrm{D}_{2}=3$ partes de água e 2 de biofertilizante $(40 \%)$ e $\mathrm{D}_{3}=2$ partes de água e 3 de biofertilizante $(60 \%)$. Foram avaliados por método não destrutivo a área foliar total e a área foliar unitária da figueira. Evidenciou-se a diferença significativa entre os ambientes estudados, sendo que o ambiente da estufa proporcionou maior desenvolvimento na cultura da figueira, seguido pelo ambiente Latada e pelo ambiente de Campo, respectivamente.

Palavras-chave: ficus carica L., fertilizante orgânico, ambiente protegido.

\section{LEAF AREA OF THE COMMON FIG UNDER (BOVINE) BIOFERTILIZER FERTIGATION IN THREE CULTIVATION ENVIRONMENTS}

\footnotetext{
ABSTRACT

${ }^{1}$ Engenheira Agrônoma. Mestre em Irrigação e Drenagem. Faculdade Tecnológica do Centec - FATEC Sertão Central. Av. Geraldo Bizarria de Carvalho, 2 - Vila Betania, Quixeramobim - CE, Brasil. CEP: 63800-000. cristianeceledonio@ yahoo.com.br

${ }^{2}$ Engenheiro Agrônomo. Doutor em Agronomia. Av. Francisco Mota, 572 Bairro Costa e Silva Mossoró-RN, Brasil. CEP: 59.625-900. Bloco de Pós Graduação, Campus Leste, Universidade Federal Rural do Semiárido - UFERSA. Mossoró-RN. jfmedeir@ufersa.edu.br

${ }^{3}$ Engenheiro Agrônomo. Doutor em Irrigação e Drenagem. Universidade Federal do Ceará - UFC. Campus do Pici, Bl. 804 S/N. Planalto do Pici. CEP: 60455-760. Fortaleza-CE, Brasil. thales@ufc.br

${ }^{4}$ Engenheiro Agrônomo. Doutor em Engenharia Agrícola. Instituto Federal do Piauí - IFPI. Campus São João do Piauí. Travessa 7 de setembro S/N, Centro. CEP: 64760-000. Tel. (89) 999467487. São João do Piauí-PI. kleiton.rocha@ifpi.edu.br

${ }^{5}$ Engenheiro Agrônomo. Universidade Federal do Ceará. Campus do Pici, Bl. 804 S/N. Planalto do Pici. CEP: 60455-760. Fortaleza-CE, Brasil. gregoriohermes@yahoo.com.br
} 
This study was aimed at determining the environment type and the (bovine) biofertilizer dose (applied through fertigation) which provide the largest fig leaf area under the semi-arid climate. This study was conducted in the Chapada do Apodi, Ceará state, Brazil. The design was that of completely randomized blocks with four replications. Treatments consist of combination of three environment types (trellis, greenhouse and field) and five fertigated (with biofertilizer) levels: four doses of biofertilizer and one dose of mineral fertilizer applied at $15,30,45,60,75$ and 90 days after formative pruning. The solution for each dose was obtained by dilution of biofertilizer with water in the following proportions: $\mathrm{D}_{0}=5$ parts water $(0 \%), \mathrm{D}_{1}=4$ parts water and 1 part of biofertilizer $(20 \%), \mathrm{D}_{2}=3$ parts water and 2 parts biofertilizer $(40 \%)$ and $\mathrm{D}_{3}=2$ parts water and 3 parts biofertilizer $(60 \%)$. The total leaf area and average leaf area of the fig tree were determined by non-destructive methods. The experiment highlighted the different development support by each environment, with the greenhouse environment providing greater leaf area development in the fig tree culture, followed by the trellis environment and by the field environment, respectively.

Keywords: ficus carica L., organic fertilizer, protected environment.

\section{INTRODUÇÃO}

A fruticultura é uma das atividades econômicas em ascensão no Brasil. Hoje, muitos já apontam o Brasil como o maior produtor de frutas tropicais do mundo devido ao incentivo do governo e a excelente localização geográfica, o que proporciona boas condições climáticas, além de favoráveis características de solo e de disponibilidade hídrica (FONSECA et al., 2006).

Novas fruteiras são importantes como forma de diversificação de produção como as culturas de clima temperado. O figo, pelas suas habilidades de adaptação, pode ser umas dessas alternativas.

No nordeste do país, o Governo do Estado da Paraíba está estimulando a produção de figo-da-índia, como alternativa para a geração de oportunidades de trabalho no campo. O Governo do Paraíba criou uma nova alternativa para a geração de oportunidades de renda no campo, ao estimular a produção de figo-da-índia. O cultivo de figo-da-índia irá aproveitar áreas marginais, permitindo ao homem do campo novas técnicas de convivência com o semiárido (SEGANTINI et al., 2010).

A análise de área foliar é um método de grande utilidade para a avaliação das diferenças no comportamento de cultivares influenciada por práticas agronômicas, efeitos de competição ou climáticos e por fatores intrínsecos associados à fisiologia da planta (ANDRADE et al., 2005; GUIMARÃES et al., 2008).

O uso de proteção de plantas, como o uso de estufas agrícolas ou latada, tem grande potencial para aumentar a produtividade, sobretudo para pequenas áreas, possibilitando uma produção com boa qualidade mesmo no período chuvoso. A cultura da figueira produzida em ambiente protegido torna o custo de produção elevado, pois o período que não há retorno do custo da produção é de aproximadamente 6 meses (NIENOW et al., 2006). Devido aos elevados custos, precisam-se de estudos com sistemas alternativos de cobertas.

A produção orgânica poderá ser alternativa para a produção de frutas, sobretudo para pequenos produtores que trabalham em cultivo protegido e o uso de biofertilizante pode substituir os fertilizantes minerais, entretanto, necessita-se de doses apropriadas deste insumo. Dentre os insumos orgânicos possíveis de utilização, o biofertilizante comum, constituído na forma líquida sob condições anaeróbicas, além de fornecer nitrogênio, fósforo, potássio, cálcio, magnésio, enxofre e micronutrientes, pode também exercer as funções de fungicida, bactericida, nematicida e não é prejudicial aos inimigos naturais (CELEDONIO et al., 2013).

Apesar de vários estudos terem demonstrado a possibilidade do biofertilizante aplicado no solo ser fonte de adubação para 


\section{ÁREA FOLIAR DA FIGUEIRA EM TRÊS AMBIENTES DE CULTIVO, SOB FERTIRRIGAÇÃO DE BIOFERTILIZANTE BOVINO}

satisfazer as exigências nutricionais das plantas sobre o crescimento, trocas gasosas e a produtividade (SOUSA et al., 2014; DINIZ et al., 2011; SILVA et al., 2011; LIMA et al., 2012; SOUSA et al., 2013), ainda há a necessidade de se desenvolverem estudos locais, visando caracterizar física e quimicamente $\mathrm{o}$ esterco de bovinos nas diversas formas de armazenamento e tratamento adotados, evitando-se assim a recomendação de dosagens excessivas ou mesmo subdosagens que implicariam na perda de elementos fertilizantes ou baixas produtividades das culturas, respectivamente (BARCELOS, 1991).

Uma das limitações à expansão do cultivo para o mercado in natura é a alta perecibilidade do fruto no campo, devido às chuvas, e na póscolheita, por podridões e desidratação, exigindo mercado garantido e de comercialização rápida. A produção em ambiente protegido corresponde a 41 e $43 \mathrm{t} \mathrm{ha}^{-1}$, em plantas no segundo e terceiro anos de cultivo, o que representa um acréscimo médio de $40 \%$ em relação aos máximos rendimentos obtidos em cultivo a campo, no Brasil, além de evitar as podridões e rachaduras nos frutos (NIENOW et al., 2006).
Diante do exposto, o presente trabalho teve como objetivos determinar o tipo de ambiente e a dose de biofertilizante bovino aplicado via fertirrigação que proporcione a maior área foliar da figueira nas condições climáticas do semiárido.

\section{MATERIAL E METÓDOS}

O trabalho foi conduzido em uma área experimental, localizada em Limoeiro do Norte-Ceará $\left(05^{\circ} 06^{\prime} 38^{\prime \prime} \quad \mathrm{S}\right.$; 37 32'21" W; Altitude de 145,95 m). As condições climáticas da área são: umidade relativa do ar, precipitação pluvial e temperatura do ar de $73,3 \%, 906,1 \mathrm{~mm}$ e $26,5{ }^{\circ} \mathrm{C}$, respectivamente (1976-2005).

As condições ambientais no experimento foram monitoradas por duas estações meteorológicas, uma convencional e outra automática, instaladas a $50 \mathrm{~m}$. No interior dos ambientes protegidos (latada e estufa).

Os solos da região são caracterizados como sendo de boa fertilidade, apresentando pH natural de neutro a alcalino. È classificado como Cambissolo Vermelho Amarelo Eutrófico, de textura franco-argiloso-arenoso, com argila de atividade alta a fraca (características físico-químicas na Tabela 1).

Tabela 1. Análises química e física do solo

\begin{tabular}{|c|c|c|c|c|c|c|c|c|}
\hline \multirow{2}{*}{ ID } & $\bar{K}$ & $\mathrm{Ca}$ & $\mathrm{Mg}$ & $\mathrm{Na}$ & $\mathrm{Al}$ & $\mathrm{H}+\mathrm{Al}$ & \multirow[t]{2}{*}{ SB } & \multirow[t]{2}{*}{ CTC } \\
\hline & \multicolumn{6}{|c|}{${ }^{-}$} & & \\
\hline PROF.: $0-20 \mathrm{~cm}$ & 9,3 & 122 & 29 & 3 & N.D. ${ }^{1}$ & 31,4 & 160,8 & 192,2 \\
\hline PROF.: 20-40 cm & 8,8 & 135 & 49,5 & 0,6 & N.D. & 21,5 & 193,3 & 214,8 \\
\hline \multirow{2}{*}{ ID } & $\mathrm{C}$ & M.O. & $\mathrm{pH}$ & $\mathrm{P}$ & V & PST & M & $\mathrm{CE}$ \\
\hline & \multicolumn{2}{|c|}{---( $\left.\mathrm{g} \mathrm{kg}^{-1}\right)^{----}$} & \multicolumn{3}{|c|}{$\mathrm{mg} \mathrm{dm} \mathrm{m}^{-3}$} & -----\%---- & \multicolumn{2}{|r|}{$\mathrm{dS} \mathrm{m}^{-}$} \\
\hline PROF.: $0-20 \mathrm{~cm}$ & 13,8 & 23,8 & 6 & 57 & 84 & 2 & 0 & 1 \\
\hline \multirow[t]{2}{*}{ PROF.: 20-40 cm } & 5,9 & 10,1 & 6,3 & N.D. & 90 & 0 & 0 & 0,2 \\
\hline & \multicolumn{5}{|c|}{ Composição granulométrica $\left(\mathrm{g} \mathrm{kg}^{-1}\right)$} & \multicolumn{3}{|c|}{ Densidade $\left(\mathrm{kg} \mathrm{dm}^{-3}\right)$} \\
\hline ID & \multicolumn{2}{|c|}{ Areia Grossa } & $\begin{array}{c}\text { Areia } \\
\text { Fina }\end{array}$ & Silte & Argila & \multicolumn{2}{|c|}{ Solo } & Part. \\
\hline PROF.: $0-20 \mathrm{~cm}$ & \multicolumn{2}{|c|}{362} & 195 & 256 & 185 & \multicolumn{2}{|c|}{1,39} & 2,78 \\
\hline PROF.: 20-40 cm & \multicolumn{2}{|c|}{218} & 159 & 314 & 309 & \multicolumn{2}{|c|}{1,3} & 2,85 \\
\hline
\end{tabular}

(1) Não determinado 
O delineamento experimental utilizado foi em blocos completos ao acaso, com quatro repetições. Os tratamentos consistiram da combinação de três tipos de ambientes (latada, estufa e campo) e cinco níveis de adubação: quatro doses de biofertilizante e uma adubação mineral. As doses do biofertilizante foram obtidas pela aplicação de três litros da solução por planta, a cada 15 dias. A solução para cada dose foi obtida pela diluição do biofertilizante em água nas seguintes proporções: $\mathrm{D}_{0}=$ zero parte de biofertilizante e 5 partes de água, $\mathrm{D}_{1}=$ 4 partes de água e 1 de biofertilizante (20\%), $\mathrm{D}_{2}=3$ partes de água e 2 de biofertilizante $(40 \%)$ e $D_{3}=2$ partes de água e 3 de biofertilizante $(60 \%)$.

Cada parcela experimental correspondeu a uma fileira de 4 plantas, sendo que a área onde foram feitas as determinações (área útil) esteve ocupada pelas 2 plantas do centro da fileira.

O ambiente tipo latada tem as laterais abertas, cuja estrutura é sustentada por coluna de madeira, coberta de polietileno de baixa densidade. $O$ ambiente constituído de uma estufa agrícola possuía as seguintes características: altura na parte central de 4,2 m e 3,0 $\mathrm{m}$ de pé direito, sendo a estrutura construída em madeira, com teto em forma de arco de elipse, de ferro galvanizado e cobertura com polietileno de baixa densidade e tela de sombreamento. As laterais foram fechadas com tela, com espaços de $3,0 \mathrm{~mm}$. O terceiro ambiente foi a campo aberto (ao ar livre) e todos eles tiveram as mesmas dimensões de superfície, ou seja, $32 \mathrm{~m}$ de comprimento e $6,4 \mathrm{~m}$ de largura.

A variedade utilizada foi a Roxo de Valinhos com espaçamento 2,0 x 1,5 m (2,0 m entre fileira de plantas e 1,50 m entre plantas na fileira). Foi realizada uma adubação de fundação com 20 litros de esterco de curral curtido por cova e adição de 300 gramas de MAP, com a composição de $11 \%$ de N, $52 \%$ de $\mathrm{P}_{2} \mathrm{O}_{5}, 0 \mathrm{~K}_{2} \mathrm{O}$ e micronutrientes. As adubações complementares foram feitas de acordo com a análise química do solo e as recomendações para o cultivo do figo.

Após a constituição dos ambientes, latada e estufa confeccionadas, fez-se a marcação das linhas de plantio (a cada 2,0 m), e a abertura de covas a cada $1,5 \mathrm{~m}$ na linha de plantio (com 40 $\mathrm{cm}$ de profundidade). As mudas foram fornecidas por uma empresa especializada, onde as mesmas foram originadas através de estacas, com enraizamento de plantas matrizes da propriedade citada, tendo sido cultivadas em solos nos sacos plásticos.

A irrigação foi realizada por meio de tubos de polietileno com gotejadores integrados na linha (online), com uma vazão de 2 L.h $^{-1}, 4$ gotejadores por planta totalizando uma vazão de $8,0 \mathrm{~L}^{-h^{-1}}$ por planta. A quantidade de água aplicada (Tabela 2) foi de acordo com as necessidades hídricas da cultura.

Tabela 2. Valores mensais das lâminas aplicadas por ambiente de cultivo: (CA), (EST) e (LT) a partir do transplantio ao final do $1^{\circ}$ ciclo da Figueira

\begin{tabular}{ccccc}
\hline Meses & \multicolumn{4}{c}{ Lâmina aplicada (mm) } \\
\hline & Sem Pe* & Com Pe & EST & LT \\
\cline { 2 - 5 } & 18,18 & 12,73 & 13,72 & 15,8 \\
Out & 52,43 & 52,43 & 39,48 & 45,55 \\
Nov & 51,51 & 32,87 & 38,64 & 44,73 \\
Dez & 122,12 & 98,03 & 91,84 & 106,8 \\
\hline Subtotal & 76,56 & 38,01 & 56,4 & 66,36 \\
Jan & 74,52 & 20,78 & 53,89 & 64,47 \\
Fev & 85,87 & 33,7 & 61,95 & 74,28 \\
Mar & 78,96 & 44,64 & 61,95 & 68,25 \\
Abr & 49,69 & 25,09 & 34,86 & 42,86
\end{tabular}


ÁREA FOLIAR DA FIGUEIRA EM TRÊS AMBIENTES DE CULTIVO, SOB FERTIRRIGAÇÃO DE BIOFERTILIZANTE BOVINO

\begin{tabular}{ccccc} 
Jun & 95,79 & 91,17 & 69,54 & 82,91 \\
Jul & 91,16 & 87,42 & 68,66 & 81,57 \\
\hline Subtotal & 552,55 & 340,81 & 407,26 & 480,7 \\
\hline Total & 674,67 & 438,84 & 499,09 & 586,78 \\
\hline
\end{tabular}

*Precipitação efetiva.

Quando as plantas atingiram uma altura média de 25 a $30 \mathrm{~cm}$, aproximadamente 60 dias após o plantio (DAP), procedeu-se a poda do ramo principal, classificado como a $1^{\mathrm{a}}$ poda, para a condução e a formação da estrutura da planta, onde foram deixados três ramos, em forma de taça.

Quanto aos tratamentos fitossanitários, realizou-se um controle preventivo mensal extrato de "nim indiano", na quantidade de 1 litro de extrato para cada 150 litros de água.

$\mathrm{O}$ processo de fabricação do biofertilizante líquido, na ausência de ar (anaeróbio ou metanogênico), foi obtido a partir da fermentação em sistema fechado com esterco fresco de gado durante aproximadamente 30 dias; tempo necessário para ocorrer o metabolismo de alterações nos componentes do esterco, mediante ação de microorganismos, liberando os macros e micros nutrientes e formando proteínas, vitaminas e hormônios, aumentando a sua disponibilidade para promover o crescimento das plantas, seguindo a metodologia apresentada por Santos (1992).

O biofertilizante foi preparado em bombonas plásticas de 200 litros contendo esterco bovino fresco e água na proporção de $50 \%$, por um período de trinta dias, na ausência de ar, com a proporção de $50 \%$ de água e $50 \%$ de esterco bovino, deixando-se um espaço vazio de 15 a $20 \mathrm{~cm}$ de altura no seu interior, depois fechadas hermeticamente. $\mathrm{Na}$ tampa foi adaptada uma mangueira com a outra extremidade mergulhada num recipiente com água na altura de $20 \mathrm{~cm}$, para a saída de gases. $\mathrm{O}$ biofertilizante foi analisado, quimicamente, visando a obtenção das quantidades dos nutrientes existentes em cada proporção aplicada, ou seja, ao nível de $20 \%$, $40 \%$ e $60 \%$ (Tabela 3).

Tabela 3. Análise Química do biofertilizante nas proporções de 20, 40 e $60 \%$

\begin{tabular}{|c|c|c|c|c|c|c|c|c|c|c|c|c|}
\hline \multirow{2}{*}{ IDENT. } & \multicolumn{6}{|c|}{ MACRONUTRIENTES $\left(\mathrm{g} \mathrm{L}^{-1}\right)$} & \multicolumn{6}{|c|}{ MICRONUTRIENTES $\left(\mathrm{mg} \mathrm{L}^{-1}\right)$} \\
\hline & $\mathrm{N}$ & $\mathrm{P}$ & $\mathrm{K}$ & $\mathrm{Ca}$ & $\mathrm{Mg}$ & $S$ & $\mathrm{Fe}$ & $\mathrm{Zn}$ & $\mathrm{Cu}$ & $\mathrm{Mn}$ & $\mathrm{B}$ & $\mathrm{Na}$ \\
\hline $20 \% \mathrm{BIO}$ & 0,14 & 0,22 & 0,25 & 0,11 & 0,06 & 0,05 & 15,5 & 0,02 & 0,02 & 1,86 & 0,94 & 45 \\
\hline $40 \% \mathrm{BIO}$ & 0,23 & 0,23 & 0,49 & 0,24 & 0,11 & 0,08 & 30,1 & 0,80 & 0,02 & 3,40 & 1,09 & 52 \\
\hline $60 \% \mathrm{BIO}$ & 0,40 & 0,32 & 0,68 & 0,38 & 0,17 & 0,12 & 44,4 & 2,38 & 1,06 & 5,28 & 1,38 & 60 \\
\hline IDENT. & \multicolumn{3}{|c|}{$\mathrm{CE}\left(\mathrm{dS} \mathrm{m} \mathrm{m}^{-1}\right)$} & \multicolumn{3}{|c|}{$\mathrm{C}(\%)$} & \multicolumn{2}{|c|}{ M. O. } & \multicolumn{2}{|r|}{$\mathrm{C} / \mathrm{N}$} & \multicolumn{2}{|c|}{$\mathrm{pH}$} \\
\hline $20 \% \mathrm{BIO}$ & \multicolumn{2}{|c|}{1,79} & & \multicolumn{2}{|c|}{0,13} & & \multicolumn{2}{|c|}{0,24} & \multicolumn{2}{|r|}{10} & \multicolumn{2}{|c|}{8,05} \\
\hline $40 \% \mathrm{BIO}$ & \multicolumn{2}{|c|}{3,18} & & \multicolumn{2}{|c|}{0,48} & & \multicolumn{2}{|c|}{0,87} & & 21 & \multicolumn{2}{|c|}{8,29} \\
\hline $60 \% \mathrm{BIO}$ & \multicolumn{2}{|c|}{4,52} & & \multicolumn{2}{|c|}{0,47} & & \multicolumn{2}{|c|}{0,85} & & 12 & \multicolumn{2}{|c|}{8,14} \\
\hline
\end{tabular}

Durante a condução do experimento aos $(15,30,45,60,75,90$ dias após a poda de condução) foram avaliados por método não destrutivo, a área foliar total e a área foliar unitária da figueira.

A medição de folhas para cálculo de área foliar é um dos mais adequados, pois é rápido, simples, independente de equipamentos complexos e não destrói a planta. Vários autores propuseram métodos similares para outras culturas (LOPES et al., 2004; BIANCO et al., 2005; 2007).

A área foliar unitária foi obtida por meio da fotografia da folha mais representativa da 
planta nomeada como (folha índice), retirada em uma base de cartolina branca utilizando-se como referência cartesiana duas réguas milimétricas. As fotos obtidas em campo foram avaliadas pelo programa computacional Sigma Scan ${ }^{\circledR}$ Pró v. 5.0, para que fosse determinada a área foliar da folha índice. Em cada parcela, a medição foi feita em duas plantas e foram tomadas duas fotos da mesma folha para se obter uma maior precisão na leitura do programa, para depois se fazer a média entre as duas fotos.

Para estimar a área foliar total da planta (AFT), utilizou-se a equação (1).

$$
A F T=N F \cdot A F U \cdot F
$$

Em que,

$\mathrm{NF}$ - número de folhas por planta;

$\mathrm{AFu}$-área da folha índice, $\mathrm{cm}^{2}$

$\mathrm{F}$ - fator de forma que corresponde a razão entre a área média das folhas e a área da folha índice.

Para determinar o fator $\mathrm{F}$, tomou-se aos 65 dias após a poda, 30 plantas; que representavam os diferentes ambientes, doses de adubação e plantas com diferentes tamanhos, mediu-se as seguintes dimensões (largura máxima da folha (L) e o comprimento da nervura principal (C), inclusive da folha índice e contou-se o número de folhas.

Para se calcular a área de cada folha a partir das suas dimensões, utilizou-se o banco de dados das fotos das folhas representativas das plantas retiradas em todas as épocas. Em cada foto, mediram-se a largura e o comprimento das folhas e tomou-se a área foliar medida pelo programa de computador
(AFu), obtendo-se a Equação (2) com o auxilio de planilha eletrônica.

$$
A F u=2,9239(C . L)^{0,7211}\left(\mathrm{r}^{2}=0,79\right)
$$

\section{$\mathrm{AFu}$ - Área Foliar Unitária \\ C- Comprimento da nervura principal \\ L- Largura da folha}

Com a estimativa da área foliar de todas as folhas, utilizando-se a Equação (2), determinou-se a área media das folhas, que dividido pela área da folha índice obteve-se o fator de forma média ( $\mathrm{F}=0,88 \pm 0,05)$, sendo $\pm 0,05$ o intervalo de confiança para $5 \%$ de probabilidade pelo teste "T".

Os dados foram submetidos à análise de variância (ANOVA), e análise de regressão polinomial, considerando os fatores tipos de ambiente (Campo, Estufa e Latada), níveis de adubação (doses de biofertilizante e adubação mineral) e dias após a poda de formação (15, $30,45,60,75,90)$. Os valores médios foram submetidos ao teste de Tukey a 0,05 de probabilidade e os efeitos das doses de biofertilizante foram submetidos à análise de regressão polinomial.

\section{RESULTADOS E DISCUSSÃO}

A Tabela 4 da análise de variância demonstrou que houve interação tripla (IDADE $x$ DOSE x AMBIENTE) para área foliar. Esta também foi significativa às interações duplas IDADE $x$ AMBIENTE $e$ DOSE $x$ AMBIENTE.

Tabela 4. Análise de variância para as características da figueira: área foliar $\left(\mathrm{cm}^{2}\right)$ e área foliar unitária $\left(\mathrm{cm}^{2}\right)$, quando cultivada sobre diferentes ambientes (AMB) e doses de biofertilizante e uma dose de adubação mineral (DOSES), ao longo de 90 dias após poda de formação (IDADE).

\begin{tabular}{|c|c|c|c|}
\hline FV & GL & AREA FOLIAR $\left(\mathrm{cm}^{2}\right)$ & AF UNITÁRIA $\left(\mathrm{cm}^{2}\right)$ \\
\hline \multicolumn{4}{|c|}{ Estatística F } \\
\hline $\mathrm{BL}(\mathrm{AMB})$ & 8 & $1,3^{\mathrm{ns}}$ & $1,6^{\mathrm{ns}}$ \\
\hline
\end{tabular}

$$
\text { VARIÁVEIS }
$$


ÁREA FOLIAR DA FIGUEIRA EM TRÊS AMBIENTES DE CULTIVO, SOB FERTIRRIGAÇÃO DE BIOFERTILIZANTE BOVINO

\begin{tabular}{cccc} 
AMB & 2 & $70,3^{* *}$ & $27,7^{*}$ \\
DOSE & 4 & $0,4^{\mathrm{ns}}$ & $1,3^{\mathrm{ns}}$ \\
DOSE*AMB & 8 & $3,0^{* *}$ & $3,3^{\mathrm{ns}}$ \\
ERRO(A) & 36 & - & - \\
DAP & 5 & $123^{* *}$ & $315,5^{\mathrm{ns}}$ \\
DAP*DOSE & 20 & $1,1^{\mathrm{ns}}$ & $1,2^{*}$ \\
DAP*AMB & 10 & $10,9^{* *}$ & $5,8^{*}$ \\
DAP*DOSE*AMB & 40 & $1,6^{*}$ & $1,0^{\text {ns }}$ \\
Resíduo & 225 & - & - \\
Média & & 9512,5 & 202,2 \\
CV1 $(\%)$ & & 39,3 & 33,1 \\
CV2 $(\%)$ & 30,5 & 11,8 \\
\hline
\end{tabular}

*** $\mathrm{e}^{\text {ns }}$ - significativo no nível de 5\%, $1 \%$ de probabilidade pelo teste $\mathrm{F}$ e não significativo no nível de $5 \%$ de probabilidade pelo teste $\mathrm{F}$, respectivamente.

Verificou-se, através da tabela 5, que a partir dos 30 DAP e para a dose de $20 \%$ do biofertilizante, o ambiente: estufa (2) foi superior ao cultivo do ambiente campo (1), passando a ser superior para todas as doses a partir dos 45 DAP. A dose de biofertilizante proporcionou respostas diferenciadas das plantas em relação à área foliar a partir dos 60 DAP e dependendo do tipo de ambiente, de modo que em algumas ocasiões o aumento da área foliar foi favorecido com as menores doses do biofertilizante, e em outras, aumentou com doses mais elevadas. $\mathrm{O}$ mesmo aconteceu para a adubação mineral.

Tabela 5. Resumo das médias para a área foliar $\left(\mathrm{cm}^{2}\right)$ da figueira, quando cultivada sob diferentes ambientes (AMB) e doses de biofertilizante e uma adubação mineral (DOSES), ao longo de 90 dias após poda de formação (IDADE).

\begin{tabular}{ccccccc}
\hline \multirow{2}{*}{ IDADE } & \multirow{2}{*}{ AMBIENTE } & \multicolumn{5}{c}{ DOSE DE ADUBAÇÃO } \\
\cline { 2 - 6 } & 1 & 0 & $20 \%$ & $40 \%$ & $60 \%$ & MINERAL \\
\hline \multirow{2}{*}{15} & 2 & $3990 \mathrm{aA}$ & $4616 \mathrm{aA}$ & $6393 \mathrm{aA}$ & $2466 \mathrm{Aa}$ & $4333 \mathrm{aA}$ \\
& 3 & $2447 \mathrm{aA}$ & $2958 \mathrm{aA}$ & $3942 \mathrm{aA}$ & $3146 \mathrm{aA}$ & $4485 \mathrm{aA}$ \\
\hline \multirow{2}{*}{30} & 1 & $5912 \mathrm{aA}$ & $4316 \mathrm{bA}$ & $5303 \mathrm{aA}$ & $5560 \mathrm{Aa}$ & $5727 \mathrm{aA}$ \\
& 2 & $8459 \mathrm{aA}$ & $9632 \mathrm{abA}$ & $6488 \mathrm{aA}$ & $6220 \mathrm{Aa}$ & $4204 \mathrm{aA}$ \\
& 3 & $6564 \mathrm{aA}$ & $5495 \mathrm{abA}$ & $7622 \mathrm{aA}$ & $5222 \mathrm{aA}$ & $4277 \mathrm{aA}$ \\
\hline \multirow{2}{*}{45} & 1 & $6432 \mathrm{bA}$ & $6399 \mathrm{abA}$ & $6133 \mathrm{aA}$ & $5182 \mathrm{Ba}$ & $6824 \mathrm{bA}$ \\
& 2 & $13684 \mathrm{aA}$ & $10910 \mathrm{aA}$ & $9815 \mathrm{aA}$ & $11886 \mathrm{Aa}$ & $12386 \mathrm{aA}$ \\
& 3 & $9053 \mathrm{abA}$ & $4980 \mathrm{bA}$ & $6417 \mathrm{aA}$ & $9640 \mathrm{abA}$ & $7095 \mathrm{bA}$ \\
\hline \multirow{2}{*}{60} & 1 & $5091 \mathrm{bA}$ & $9155 \mathrm{bA}$ & $6416 \mathrm{bA}$ & $5049 \mathrm{Ba}$ & $5688 \mathrm{bA}$ \\
& 2 & $15106 \mathrm{aA}$ & $15184 \mathrm{aA}$ & $15284 \mathrm{aA}$ & $11003 \mathrm{Aa}$ & $15457 \mathrm{aA}$ \\
& 3 & $14807 \mathrm{aA}$ & $6809 \mathrm{bB}$ & $13204 \mathrm{aA}$ & $11748 \mathrm{aAB}$ & $10957 \mathrm{aAB}$ \\
\hline
\end{tabular}


Celedonio et al.

\begin{tabular}{rrrrrrc} 
& 1 & $7938 \mathrm{bA}$ & $8454 \mathrm{bA}$ & $8851 \mathrm{bA}$ & $5764 \mathrm{Ba}$ & $9507 \mathrm{bAB}$ \\
75 & 2 & $16459 \mathrm{aA}$ & $18838 \mathrm{aA}$ & $14813 \mathrm{aA}$ & $16429 \mathrm{Aa}$ & $15772 \mathrm{aA}$ \\
& 3 & $13333 \mathrm{aA}$ & $14621 \mathrm{aA}$ & $15217 \mathrm{aA}$ & $18278 \mathrm{aA}$ & $14935 \mathrm{aA}$ \\
\hline \multirow{2}{*}{90} & 1 & $5086 \mathrm{bB}$ & $12340 \mathrm{bA}$ & $10216 \mathrm{bAB}$ & $7900 \mathrm{Bab}$ & $7872 \mathrm{bAB}$ \\
& 2 & $18092 \mathrm{aAB}$ & $19947 \mathrm{bA}$ & $13777 \mathrm{bB}$ & $16954 \mathrm{Aab}$ & $21180 \mathrm{aA}$ \\
& 3 & $19831 \mathrm{aA}$ & $13159 \mathrm{bB}$ & $18085 \mathrm{aAB}$ & $19156 \mathrm{aA}$ & $12740 \mathrm{bB}$ \\
\hline
\end{tabular}

**Letras minúsculas configuram médias entre ambientes dentro de cada época e de cada dose de adubação, e letras maiúsculas configuram na horizontal as doses dentro de cada época e ambiente. Em cada fertirrigação realizada quinzenalmente, foi aplicado 3,0 litros por planta de solução de biofertilizante.

A dose de $0 \%$ de biofertilizante os 45 DAP, na variável área foliar, demonstrou diferença nas médias entre ambiente e idade, onde o ambiente campo se mostrou com valores inferiores aos ambientes: estufa e latada, durante o restante dos dias avaliados até a idade de 90 DAP.

$\mathrm{Na}$ dose de $20 \%$ aos 30 DAP, houve interação nos três ambientes; aos 45 e 60 DAP houve interação nos ambientes campo e latada, não havendo diferença no ambiente estufa; aos 75 DAP houve diferença apenas para o ambiente campo (1), e aos 90 DAP houve diferença para os três ambientes estudados.

Na dose de 40\%, houve diferença aos 60 e 75 DAP para o ambiente campo e aos 90 DAP a diferença foi para o ambiente: latada, demonstrando uma média maior que nos outros ambientes. Já na dose de $60 \%$, houve diferença aos 45 DAP, onde o ambiente: estufa (2) obteve uma maior média; e aos 60, 75 e 90 DAP, onde o ambiente: latada obteve uma maior área foliar em ambas.

A dosagem de $60 \%$ pode ter impedido a figueira de desenvolver, pois Medeiros e Lopes (2006) concluíram que em concentrações muito elevadas, os biofertilizantes podem causar estresse fisiológico na planta retardando seu crescimento. Sousa et al. (2012) analisando o crescimento do milho sob diferentes concentrações do biofertilizante bovino, também verificaram área foliar decrescente com o aumento na concentração de biofertilizante.

Na adubação mineral aos 45 DAP, houve diferença nos ambiente campo e latada, os mesmos diferindo da estufa (2). Aos 60 e 75
DAP apenas para o ambiente campo (1) diferiu dos outros ambientes demonstrando um menor valor. Aos 90 DAP, o ambiente: estufa não diferiu dos outros ambientes, com a estufa (2) apresentando um maior valor entre as médias.

Lima et al. (2009) pesquisando sobre a influência de diferentes tipos de biofertilizantes na área foliar do pimentão, verificaram melhores resultados com o uso do biofertilizante bovino, mas estatísticamente, de forma não significativa.

$\mathrm{Na}$ interação doses de adubação $\mathrm{x}$ idade $\mathrm{x}$ ambiente, a diferença veio aparecer aos 60 DAP, e no ambiente latada (3) com a dose de 20\%, 60\% e adubação mineral. Aos 75 DAP a dose mineral no ambiente céu aberto (1) diferiu das outras doses mostrando uma média maior que as outras doses. Aos 90 DAP no ambiente (1) só não houve diferença para a dose de $20 \%$, onde a mesma demonstrou um valor mais representativo em relação às outras doses. No ambiente (2) houve diferença para $0 \%, 40 \%$ e $60 \%$, onde as doses de $20 \%$, $40 \%$ e mineral, onde a dose de $40 \%$ apresentou uma média maior.

A área foliar teve diferença significativa, a partir dos $45 \mathrm{DAP}$, sendo obtido no ambiente estufa (2), o melhor desenvolvimento, e o ambiente campo (1) é que se mostrou menos significativo. Aos 75 e 90 DAP, o ambiente: latada (3) se equiparou ao ambiente estufa.

Segundo Chaves (2003) as alterações provocadas pelo ambiente protegido sobre a temperatura, umidade do ar, radiação fotossintética e composição atmosférica, entre outras alterações ambientais, influenciam vários aspectos fenológicos, vegetativos e produtivos da figueira. 


\section{ÁREA FOLIAR DA FIGUEIRA EM TRÊS AMBIENTES DE CULTIVO, SOB FERTIRRIGAÇÃO DE BIOFERTILIZANTE BOVINO}

$\mathrm{O}$ ambiente protegido tem os elementos micrometeorológicos modificados no seu interior, principalmente no que diz respeito à radiação solar e a velocidade do vento reduzindo e a evapotranspiração (CALVETE et al., 2005). Estas modificações ambientais causadas pelo ambiente protegido devem-se ao filme transparente que altera o balanço de radiação do sistema composto pela planta, solo e atmosfera. As temperaturas dependem das condições externas do ambiente protegido, influenciando as temperaturas máximas e mínimas as quais, são importantes quanto maior for a restrição de renovação do ar interno e quanto maior for à disponibilidade de radiação durante o dia (CALVETE et al., 2005).

A área foliar foi significativa para tratamento idade $\mathrm{x}$ ambiente, onde essa variável aos 30 DAP começou a ter diferença no teste de média apenas para a dose de $20 \%$ de biofertilizante. Aos 45 DAP, houve diferença entre as médias para as doses de $0 \%, 20 \%, 60 \%$ e Mineral, não havendo diferença entre as médias para a dose de $40 \%$ de biofertilizante. Nas idades de 60, 75 e 90 DAP, houve diferença entre as médias analisadas.

Para maior eficiência do ambiente protegido, é necessário compreender a interrelação da planta e dos fatores microclimáticos dentro do ambiente protegido. Os fatores para o desenvolvimento e crescimento da planta dizem respeito aos fisiológicos (transpiração, respiração e fotossíntese) e aos físicos (luz, temperatura, umidade e $\mathrm{CO}_{2}$ ) (TAIZ; ZEIGER, 2004).

Quanto ao ambiente: campo (1) verificase que a dose de $20 \%$ de biofertilizante demonstrou um melhor resultado, gerando uma maior área foliar ao longo da idade da figueira. A menor área foliar verificada foi com a dose de $0 \%$. Para esse ambiente, quanto à análise de regressão polinomial realizada, os coeficientes de determinação $\left(\mathrm{R}^{2}\right)$ para cada dosagem de biofertilizante, em função da idade foram os seguintes: 0,377 para a condição de $0 \%$ (menor), 0,975 para $40 \%$ de biofertilizante, ou seja, para esta dose, conclui-se que em 97,5\% dos pontos analisados podem ser explicados pelas variações da idade e da área foliar. Já para aquela, apenas $37,7 \%$ podem ser explicados.

Já no ambiente: estufa (2) as maiores área foliares verificadas foram com dosagem do fertilizante mineral, mas bem próxima ao desempenho da dosagem de $20 \%$ do biofertilizante, ao longo da idade da planta. Resultados semelhantes foram observados por Sousa et al. (2012). Já a menor área foi confirmada com a dosagem de $40 \%$ de biofertilizante, mesmo verificando que para essa condição, nos primeiros 10 a 20 DAP, proporcionou as maiores áreas foliares. Para esse ambiente, quanto à análise de regressão polinomial realizada, os coeficientes de determinação $\left(\mathrm{R}^{2}\right)$ para cada dosagem de biofertilizante, em função da idade foram os seguintes: 0,838 para a condição de $40 \%$ (menor), 0,987 (maior) para $0 \%$ de biofertilizante.

Inclusive, Araújo (2007) constatou que doses de biofertilizante bovino, aplicados ao solo, não exerceram influência significativa no crescimento do mamoeiro Baixinho de Santa Amália, quer isoladamente ou pelas interações biofertilizante $\mathrm{x}$ adubação mineral, biofertilizante $\mathrm{x}$ idade $\mathrm{e}$ biofertilizante $\mathrm{x}$ adubação mineral $x$ idade das plantas.

No ambiente: latada (3) ocorreu o oposto do ambiente: campo, pois ao final dos 100 DAP a dosagem de fertilizante mineral gerou os menores valores de área foliar. Já as maiores áreas foliares foram verificadas com dosagem do fertilizante mineral, mas bem próxima ao desempenho da dosagem de $20 \%$ do biofertilizante, ao longo da idade da planta. Para esse ambiente, quanto à análise de regressão polinomial realizada, os coeficientes de determinação $\left(\mathrm{R}^{2}\right)$ para cada dosagem de biofertilizante, em função da idade foram os seguintes: 0,834 para a condição de $20 \%$ (menor), 0,970 (maior) para $60 \%$ de biofertilizante. Com o incremento de biofertilizante é possível que a planta se desenvolva mais rapidamente, pois França et al. (2009) verificaram que o uso do biofertilizante 
bovino eleva os teores de micronutrientes no solo.

Resultado semelhante foi verificado por Farias (2008), que em experimento com a cultura do pimentão e utilizando diferentes doses de biofertilizantes, concluiu que até certa dosagem do biofertilizante, a área foliar fora crescente; e a partir desse ponto ótimo, a área foliar iniciou diminuição.

Já Maia et al. (2011) analisando a influência do uso de biofertilizantes no crescimento vegetativo (área foliar) da bananeira verificaram ao final da pesquisa que a área foliar da bananeira Nanica, não foi afetada de forma significativa pelas dosagens de biofertilizantes utilizadas.

\section{CONCLUSÕES}

Houve diferença significativa entre os ambientes estudados, sendo o ambiente: estufa o que proporcionou maior área foliar da cultura da figueira, seguido pelo ambiente: Latada e ambiente: Campo, respectivamente. Já quanto às doses de biofertilizante bovino e adubação mineral, com exceção da interação com o tipo de ambiente, as mesmas não resultaram em efeitos significativos.

\section{REFERÊNCIAS}

ANDRADE, A.C.; FONSECA, D.M. da; LOPES, R. dos S.; NASCIMENTO JÚNIOR, D. do; ARAÚJO, E.C.E.; SANTOS, E.P. dos; PRADO, C.H.B. de A. Estimativa da área foliar da mangueira (Mangifera indica L.) cvs. Tommy Atkins e Haden, utilizando dimensões lineares. Revista Brasileira de Fruticultura, v. 27, p.308-309, 2005.

ARAÚJO, F.A.R. Biofertilizante bovino e adubação mineral no mamoeiro e na fertilidade do solo. 103f. Dissertação (Mestrado em Agronomia)- Centro de Ciências Agrárias, Universidade Federal da Paraíba, Areia - PB. 2007.
BARCELOS, L. A. R. Avaliação potencial fertilizante do esterco líquido de bovinos. 101f. Dissertação (Mestrado em Agronomia). Universidade Federal de Santa Maria - UFSM, Santa Maria - RS, 1991.

BIANCO, S.; BINCO, M. S.; PAVNII, M. C. M. D.; DUARTE, D. J. Estimativa da área foliar de Ipomoea hederifolia e Ipomoea nil Roth. usando dimensões lineares do limbo foliar. Planta Daninha, v.25, n.2, p.325-329, 2007.

BIANCO, S.; PITELE, R.; BIANCO, M. S. Estimativa da área foliar de Brachiaria plantaginea usando dimensões lineares de limbo foliar. Planta Daninha, v.23, n.4, p.597601, 2005.

CALVETE, E. O.; ROCHA, H.C.; ANTUNES, O.T.; NIENOW, A.A. Morangueiro polinizado pela abelha jataí em ambiente protegido. Passo Fundo: UPF, 2005.53p.

CELEDONIO, C.A.; MEDEIROS, J.F.; SILVA, F.L.; SARAIVA, K.R.; ALBUQUERQUE, A.H.P. Crescimento da figueira em três ambientes de cultivo, sob aplicação de biofertilizante bovino via fertirrigação. Revista Brasileira de Agricultura Irrigada. v.7, n.6, Fortaleza, p. 358 - 370, 2013.

CHAVES, G. Figueira cv. Roxo de valinhos submetida a diferentes épocas de poda e número de ramos combinado com espaçamentos, em ambiente protegido. $127 \mathrm{f}$. Dissertação (Agronomia - Área de concentração Produção Vegetal). Universidade de Passo Fundo, RS, 2003.

DINIZ, A. A.; CAVALCANTE, L. F; REBEQUI, A. M.; NUNES, J. BREHM, M. A. S. Esterco líquido bovino e ureia no crescimento e produção de biomassa do maracujazeiro amarelo. Revista Ciência Agronômica, v. 42, n. 03, p. 597-604, 2011.

FARIAS, A.A. Crescimento e produção da cultura do pimentão sob diferentes dosagens 


\section{ÁREA FOLIAR DA FIGUEIRA EM TRÊS AMBIENTES DE CULTIVO, SOB FERTIRRIGAÇÃO DE BIOFERTILIZANTE BOVINO}

e concentrações de biofertilizantes. Campina Grande-PB: UEPB/PROINCI, 2008. 33p.

FONSECA, K. M.; OLIVEIRA, C. A. S.; YAMANISHI, O. K.; QUADROS, M. Crescimento da planta e produção de duas cultivares de mamão fertirrigadas com potássio em um solo de cerrado, 2006. Disponível em: <http://www.ufpel.tche.br/sbfruti/anais_xvii_cb f/climassolosnutricao/221.htm>. Acesso em: 8 fev. 2014.

FRANÇA, C. P.; MESQUITA, E. F.; CAVALCANTE, L. F.; ARAÚJO, D. L.; FARIAS, A. A.; ARAÚJO, D. L. Teores de micronutrientes em solo cultivado com mamoeiro baixinho de santa amália, tratado com biofertilizante bovino. Revista de biologia e ciências da terra. Suplemento Especial, n. 1, v.1, 2009.

GUIMARÃES, C.M.; STONE, L.F.; NEVES, P. de C.F. Eficiência produtiva de cultivares de arroz com divergência fenotípica. Revista Brasileira de Engenharia Agrícola e Ambiental, Campina Grande, v. 12, n. 6, p. 465-470, 2008.

LIMA, A.S.; CAVALCANTE, S.N.; MELO, W.B.; MAIA FILHO, F.C.F.; LIMA, R.A.; SANTOS, J.G.R.; ANDRADE, R. Efeitos de dosagens e tipos de fertilizante sobre a área foliar unitária e total de mudas de pimentão. Revista Biologia e Ciências da Terra, v.2, n.1, p. 19-24, 2009.

LIMA, J.G.A.; VIANA, T.V.A.; SOUSA, G.G.; WANDERLEY, J.A.C.; PINHEIRO NETO, L.G.; AZEVEDO, B.M. Crescimento inicial do milho fertirrigado com biofertilizante. ACSA - Agropecuária Científica no Semi-Árido,v. 8, n. 1, p. 39 - 44, jan - mar, 2012.

LOPES, C. M.; ANDRADE, I.; PEDROSO, V.; MARTINS, S. Modelos empíricos para estimativa da área foliar da videira na Casta Jaen. Ciência Técnica Vitivinicultura, v.19, n.2, p.61-75, 2004.

MAIA, P.M.E.; ALVES, F.I.S.; LIMA, A.S.; PEREIRA, R.F.; CAVALCANTE, S.N.; SANTOS, J.G.R. Crescimento vegetativo da bananeira Nanica (Musa sp) em função do uso de diferentes tipos e dosagens de biofertilizante. Caderno de Agroecologia, v.6, n.2, p. 1- 4, 2011.

MEDEIROS, M .B. de.; LOPES, J. da. S. Biofertilizantes líquidos e sustentabilidade agrícola. Bahia Agrícola, v7. n.3, Nov. 2006.

NIENOW, A.A.; CHAVES, A.; LAJÚS, C.R.; CALVETE, E.O. Produção da figueira em ambiente protegido submetida a diferentes épocas de poda e número de ramos. Revista Brasileira Fruticultura, Jaboticabal - SP, v. 28, n. 3, p. 421-424, 2006.

SANTOS, A. C. V. Biofertilizantes líquidos: o defensivo agrícola da natureza. 2 ed., rev. Niterói: EMATER - RIO, 162p. Agropecuária Fluminense, v.8, 1992.

SEGANTINI, D.M.; SILVA, A.C.C.; BOLIANI, A.C.; LEONEL, S. Fenologia da Figueira da Índia em Selvíria - MS. Revista Brasileira de Fruticultura, Jaboticabal - SP, v. 32, n. 2, p. 630-636, 2010.

SILVA, A. R. A.; BEZERRA, F.M.L.; SOUSA, C. C. M.; PEREIRA FILHO, J. V.; FREITAS, C. A. S. Desempenho de cultivares de girassol sob diferentes lâminas de irrigação no Vale do Curu, CE. Revista Ciência Agronômica, v. 42, n. 01, p.57-64, 2011.

SOUSA, G.G.; MARINHO, A.B.; ALBUQUERQUE, A.H.P.; VIANA, T.V.A.; AZEVEDO, B.M. Crescimento inicial do milho sob diferentes concentrações de biofertilizante bovino com águas salinas. Ciência 
Celedonio et al.

Agronômica., v. 43, n. 2, p. 237-245, abr-jun, 2012.

SOUSA, G. G.; VIANA, T. V. A.; DIAS, C. N.; SILVA, G. L.; AZEVEDO, B. M. Lâminas de irrigação para a cultura do gergelim com biofertilizante bovino. Magistra, Cruz das Almas - BA, V. 26, n. 3, p. 347 - 356, Jul./Set. 2014.
SOUSA, G. G.; VIANA, T. V. A.; BRAGA, E. S.; AZEVEDO, B. M.; MARINHO, A. B.; BORGES, F. R. M. Fertirrigação com biofertilizante bovino: Efeitos no crescimento, trocas gasosas e na produtividade do pinhãomanso. Revista Brasileira de Ciências Agrárias, v.8, n.3, p.503-509, 2013.

TAIZ, L.; ZEIGER, E. Fisiologia Vegetal. $3^{\circ}$ ed. Porto Alegre: Artmed, 2004.719p 